\title{
Les-Granges-Gontardes, Logis de Berre
}

RD 458, 541 et 457

\section{Anne-Claude Rémy}

\section{(2) OpenEdition}

\section{Journals}

Édition électronique

URL : http://journals.openedition.org/adlfi/1768

ISSN : 2114-0502

Éditeur

Ministère de la culture

Référence électronique

Anne-Claude Rémy, "Les-Granges-Gontardes, Logis de Berre », ADLFI. Archéologie de la FranceInformations [En ligne], Rhône-Alpes, mis en ligne le 01 mars 2008, consulté le 25 avril 2019. URL http://journals.openedition.org/adlfi/1768

Ce document a été généré automatiquement le 25 avril 2019

(C) Ministère de la Culture et de la Communication, CNRS 


\section{Les-Granges-Gontardes, Logis de Berre}

RD 458, 541 et 457

Anne-Claude Rémy

Identifiant de l'opération archéologique : 9922

Date de l'opération : 2008 (EX)

1 Les observations faites lors d'un diagnostic mené à l'emplacement d'un futur carrefour giratoire permettent d'attester la présence de vestiges dans les deux sondages réalisés et dans le fossé de la route. L'état de conservation est différent selon la localisation des sondages, l'un en haut de talus, le second en pied de butte et en bord de route, en contrebas de $2,10 \mathrm{~m}$.

Dans le premier sondage, un colluvionnement recouvre un remblai de démolition, selon un fort pendage nord-sud. Il s'agit d'un bâtiment effondré dont la nature n'est pas caractérisée. Il comporte des cloisons ou des murets constitués de tuiles maçonnées qui forment des petites pièces. Sous la démolition est conservée une série de niveaux de sol alternant avec des niveaux d'occupations.

3 Les vestiges du second sondage ont été partiellement arasés et probablement décaissés par les travaux d'aménagement de la route. On note la présence d'un niveau de sol et d'un mur orienté est-ouest. Il n'est d'ailleurs pas exclu que $\mathrm{Cl}$. Boisse qui fouilla précédemment une partie de ce site, ait déjà repéré ces découvertes. Malgré l'arasement des structures, la stratigraphie reste conséquente. Les vestiges archéologiques apparaissent à une profondeur de $1 \mathrm{~m}$ à $1,20 \mathrm{~m}$. Une seule période a été mise au jour, bien que du mobilier résiduel précoce (seconde moitié du $1^{\mathrm{er}} \mathrm{s}$. av. J.-C.) ait été trouvé dans les niveaux antiques. La céramique présente dans les différents niveaux date le début de l'occupation de l'époque augustéenne, puis de la première moitié du $1^{\mathrm{er}} \mathrm{s}$. apr. J.-C. Elle se poursuit audelà puisque des tessons $\mathrm{du}_{\mathrm{Il}}^{\mathrm{e}} \mathrm{s}$. apr.J.-C. ont été découverts dans un remblai antique 
recouvrant la destruction. L'ensemble est recouvert par un épais colluvionnement daté par la céramique vernissée du XIX ${ }^{2}$.

4 Anne-Claude Rémy INRAP

INDEX

operation Expertise (EX)

Index géographique : Rhône-Alpes, Drôme (26), Granges-Gontardes

Index chronologique : Haut-Empire

Thèmes : céramique gallo-romaine, fondation de bâtiment, mur, remblai

\section{AUTEUR}

\section{ANNE-CLAUDE RÉMY}

INRAP 